\title{
Gut-Liver Axis in Nonalcoholic Fatty Liver Disease: the Impact of the Metagenome, End Products, and the Epithelial and Vascular Barriers
}

\author{
Antonio Gil-Gómez, $\mathrm{PhD}^{1,2}$ Paola Brescia, $\mathrm{PhD}^{3}$ Maria Rescigno, $\mathrm{PhD}^{3}$ \\ Manuel Romero-Gómez, MD, PhD ${ }^{1,2,4}$
}

${ }^{1}$ SeLiver Group at Institute of Biomedicine of Seville (IBiS), Virgen del Rocio University Hospital/CSIC/University of Seville, Seville, Spain

2 Hepatic and Digestive Diseases Networking Biomedical Research Centre (CIBERehd), Instituto de Salud Carlos III, Madrid, Spain

${ }^{3}$ Humanitas Clinical and Research Center - IRCCS, Rozzano, Milan, Italy

${ }^{4}$ UCM Digestive Diseases, Virgen del Rocío University Hospital,

Seville, Spain

Semin Liver Dis 2021;41:191-205.

\begin{abstract}
Address for correspondence Manuel Romero-Gómez, MD, PhD, Full Professor of Medicine, Unit for the Clinical Management of Digestive Diseases, Virgen del Rocío University Hospital, Av. Manuel Siurot, s/n, 41013 Seville, Spain (e-mail: mromerogomez@us.es).
\end{abstract}

Nonalcoholic fatty liver disease (NAFLD) is a systemic, dynamic, heterogeneous, and multiaxis entity. NAFLD has been linked to extrahepatic malignancies such as chronic kidney disease, cardiac disease, sleep apnea syndrome, polycystic ovary syndrome, inflammatory disorders, brain aging, and cognitive impairment. ${ }^{1-3}$ It is a dynamic entity and progression from steatosis to steatohepatitis and fibrosis seems to occur more often than regression, but both changes have been reported. ${ }^{4,5}$ Moreover, it is a heterogeneous disease with several phenotypes depending on if people are obese or lean, have metabolic syndrome or are metabolically healthy, and have type 2 diabetes (T2D) or do not.

The pathogenesis of NAFLD remains poorly understood, but it is known to be related to multiple insults that occur synergistically, including triglyceride accumulation, insulin resistance, de novo lipogenesis, oxidative stress and mitochondrial dysfunc- tion, altered mechanisms of apoptosis, and autophagy promoting inflammation and fibrosis. ${ }^{6,7}$ Accumulating evidence has also revealed the prominent role of genetic variants, environmental factors, and changes in the gut microbiota (GM) under complex interactions that result in altered lipid metabolism and accumulation within the hepatocytes. Moreover, the microbiota plays a role in regulating the balance between pro- and antiinflammatory signals, which may contribute to the progression to nonalcoholic steatohepatitis (NASH). ${ }^{8-10}$

Nevertheless, there is still an urgent need to understand the pathophysiologic implications of the altered GM in NAFLD, which could help improve diagnostics and identify patient subgroups and new targets in the era of personalized medicine. Throughout this review, we describe recently uncovered evidence for the role of the gut microbiome and its metabolites in the pathophysiology of NAFLD. 


\section{Gut-Liver Axis}

\section{Anatomical Characteristics of the Gut-Liver Axis}

The term gut-liver axis refers to the relationship between the gut, its microbiota, and the liver, which is a consequence of the close anatomical and functional bidirectional interaction through the biliary tract and the portal to the systemic circulation. The liver receives through the portal blood, in addition to blood and energy supply, gut-derived toxic elements, including bacteria with their metabolites and subproducts (pathogenassociated molecular pattern [PAMP] and damage-associated molecular pattern), which either actively or passively manage to cross from the gut barrier, reach the systemic circulation, and play a role in liver injury. ${ }^{11}$ Conversely, the liver communicates with the intestine by releasing bile acids (BAs) and other metabolites into the biliary tract and systemic circulation, which in turn will control metabolic functions and the composition of the microbiota. ${ }^{12}$ This relationship is regulated and stabilized by a complex network encompassing a metabolic, immune, and neuroendocrine cross-talk between the GM and the liver. ${ }^{13}$

\section{Gut Microbiota}

The GM is a complex ecosystem consisting of bacteria, archaea, protists, fungi, and viruses, which plays important roles in physiological and pathological conditions in the human body. The GM exists in a precise and complex symbiosis among single organisms and with the human body, with its composition being shaped by environmental and host-related factors such as the diet, drugs, physical activity, circadian rhythms, and geography. Although the microbial profile varies among individuals, the composition and relative abundance of species are comparable between healthy people. Despite a wide diversity, four main phyla dominate: Firmicutes, Bacteroidetes, Actinobacteria, and Proteobacteria, the first two being $90 \%$ of the total. A rich and diverse microbiota has been characterized as a healthy microbiota, which is able to better withstand external threats. Several factors that challenge the composition of this ecosystem, such as the diet or antibiotic use, may promote dysbiosis, gut barrier dysfunction, and disturbances of the host-microbe homeostasis, which have been related to metabolic inflammation and fueling of metabolic perturbations, and are relevant events in T2D and NAFLD. ${ }^{14}$ It is now acknowledged that this control has a role in NAFLD pathogenesis, as animal studies have suggested that the GM is involved in the development of adipose tissue and hepatic steatosis. ${ }^{15}$ Indeed, high-fat diet (HFD)-fed germ-free mice accumulated less hepatic lipids than conventionally housed mice, ${ }^{16}$ and fecal microbiota transplantation from donor mice exhibiting metabolic disorders led to NAFLD development in germ-free recipient mice. ${ }^{9}$ Furthermore, another study found a positive correlation between the abundance of Lactobacillus gasseri and Lactobacillus taiwanensis and the accumulation of lipid droplets in the liver. ${ }^{17}$ In humans, an intervention study consisting in 6 weeks of a low-choline diet found a correlation between microbiota changes, such as an increase in Gammaproteobacteria and a decrease in
Erysipelotrichia, and the hepatic lipid content. ${ }^{18}$ of note, it has been suggested that the changes in microbiota composition are not stable during the progression of NAFLD, making it difficult to validate disease-specific microbiota signatures. $^{19}$

The GM also contributes to the gastrointestinal health by controlling the integrity of the intestinal epithelial and vascular barriers as well as the mucus layer. ${ }^{20,21}$ Moreover, the GM can contribute to liver fat accumulation through direct and indirect effects on the host, including appetite regulation, energy extraction from the diet, energy expenditure, and lipid handling through effects on insulin sensitivity.

\section{Metabolites Influencing Gut-Liver Axis}

The GM contributes significantly to the pool of metabolites present in the human systemic circulation (up to 10\%), featuring a systemic bioactive effect with both inflammatory and metabolic functions. ${ }^{22}$ Thus, the liver is continuously challenged by the metabolic stress induced by bacteria and their metabolites, even when in a healthy state. However, it is not yet clear whether liver diseases such as NAFLD and T2D might affect the capacity of the liver to respond to bacteria and their byproducts. Other relevant metabolites are listed in -Table 1.

\section{Short-Chain Fatty Acids}

Complex carbohydrates, such as fiber and resistant starch, and less commonly peptides are digested by different GM species leading to the release of short-chain fatty acids (SCFAs), an essential energy source for both the microbiota and the host (-Fig. 1). Acetate, propionate, and butyrate (also valeric and caproic acids) are the main SCFAs produced in the colon. ${ }^{23}$ Nevertheless, a certain amount is transported to the bloodstream through the transporters MCT-1 and SMCT-1, reaching the liver via the portal vein. Once in the liver, they can enter the tricarboxylic acid cycle and be used as an energy source, but they can also function as signaling molecules by binding $G$-protein-coupled receptors such as GPR41, GPR43, and GPR109A. ${ }^{24}$ Indeed, they have many bioactive roles, regulating lipid and carbohydrate metabolism and controlling gut immunity and microbiota homeostasis. ${ }^{25}$

SCFAs represent an additional link between GM, obesity, insulin resistance, and NAFLD, since intestinal recognition of SCFAs promotes the release of peptide YY (PYY) and glucagon-like peptide-1 (GLP1) through the activation of Ffar2 and Ffar3 receptors and AMP-activated protein kinase (AMPK) signaling. ${ }^{26,27}$ They also increase the energy expenditure through the sympathetic nervous system; recent data from animal studies reflected an upregulation of thermogenesis genes in the liver and brown adipose tissue after stimulation with acetate and butyrate. ${ }^{28}$ Moreover, in the skeletal muscle SCFAs lead to increased oxidation of fat and decreased lipogenesis through AMPK signaling and the enzyme fatty acid synthase. ${ }^{29}$ They can also modify gene expression, since butyrate (and to a lesser extent propionate and acetate) can act as histone deacetylase inhibitors regulating, among others, genes involved in the synthesis of cholesterol. ${ }^{30}$ 
Table 1 Effect of other microbial metabolites on NAFLD via the gut-liver axis

\begin{tabular}{|l|l|l|}
\hline Metabolites & Bacterial groups & Biological functions \\
\hline $\begin{array}{l}\text { Branched-chain } \\
\text { amino acids }\end{array}$ & $\begin{array}{l}\text { Clostridium, Fusobacterium, Bacteroides, } \\
\text { Actinomyces, Propionibacterium, } \\
\text { Peptostreptococci }\end{array}$ & $\begin{array}{l}\text { Promote lipid metabolism and enhance intestinal barrier } \\
\text { function. }\end{array}$ \\
\hline $\begin{array}{l}\text { Indoles (tryptophan } \\
\text { derivatives) }\end{array}$ & $\begin{array}{l}\text { Prevotella, Bacteroides, Fusobacterium, } \\
\text { Escherichia, Clostridium }\end{array}$ & $\begin{array}{l}\text { Enhance tight junctions, modulate GLP-1 secretion, reduce } \\
\text { liver inflammation and metabolic alterations induced by } \\
\text { LPS, regulate lipogenesis mediated by cytokines and FFAs } \\
\text { on hepatocytes } 131,161,162\end{array}$ \\
\hline $\begin{array}{l}\text { Vitamins } \\
\text { Carotenoids and } \\
\text { componolic }\end{array}$ & $\begin{array}{l}\text { Bacteroidetes, Fusobacteria, } \\
\text { Proteobacteria }\end{array}$ & $\begin{array}{l}\text { Dietary and microbiota-modified vitamins can strengthen } \\
\text { innate immunity, regulate cell proliferation, and influence } \\
\text { GM composition. Vitamin E and D have been proposed as } \\
\text { treatments for NAFLD. }\end{array}$ \\
\hline Gases, 163
\end{tabular}

Abbreviations: AHR, aryl hydrocarbon receptor; FFA, free fatty acid; GABA, gamma aminobutyric acid; GM, gut microbiota; HPA, hypothalamic pituitary adrenal; LPS, lipopolysaccharide; NAFLD, nonalcoholic fatty liver disease; PXR, pregnane X receptor.

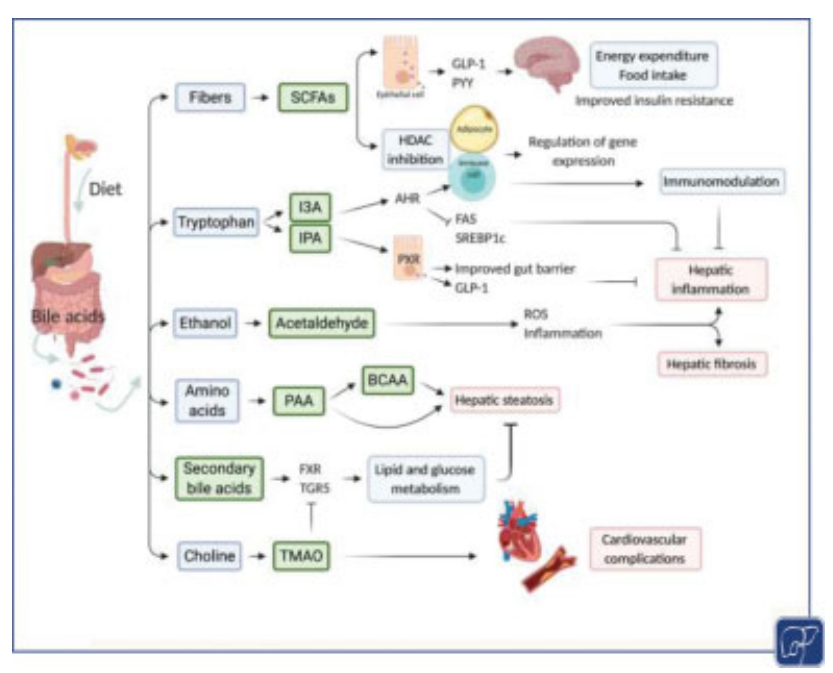

Fig. 1 The role of relevant microbiota-derived metabolites. Food components along with bile acids transformed by gut microbiota into active molecules that can elicit beneficial or detrimental responses in different organs of the body, contributing to the clinical phenotype.

Patients with T2D have a reduced abundance of butyrateproducing bacteria. ${ }^{31}$ Recent evidence has shown an association between NASH and low-fiber diet, whereas NAFLD patients fed a high-fiber diet showed improved alanine aminotransferase, aspartate aminotransferase, and cholesterol levels, possibly through promotion of the abundance of butyrate-producing bacteria. $^{32,33}$ Moreover, direct supplementation with SCFAs improved diet-induced hepatic steatosis in a mouse model. ${ }^{34}$
In a human study, propionate supplementation reduced weight gain and fat accumulation in the liver while improving insulin sensitivity. ${ }^{35}$ However, obese patients had higher levels of propionate in the stool, which suggested that either its production was increased or its absorption is disturbed. ${ }^{36}$ Further studies are needed to validate these observations and better elucidate the role of SCFAs in the pathogenesis of NAFLD.

\section{Bile Acids}

BAs are direct intermediaries in the gut-liver communication. Primary BAs (mainly chenodeoxycholic acid and cholic acid) are synthesized as glycine or taurine conjugates from cholesterol in the liver. They are secreted and stored in the gallbladder and then released in the duodenum after food intake where they play an essential role in cholesterol metabolism, lipid digestion, and the absorption of fat-soluble vitamins. ${ }^{37}$ The amount of the mainstream pool of BAs depends on the enterohepatic circulation in a two-way interaction, as the GM affects BA metabolism and the BA affects the GM composition. In this respect, the size and composition of the BA pool are controlled by the GM via the biotransformation of primary into secondary BAs (mainly deoxycholic acid and lithocholic acid), through several modifications: oxidation/epimerization, deconjugation, esterification, 7-dehydroxylation, and desulfation. ${ }^{38}$ These processes can be disrupted in NAFLD patients due to dysbiosis. Specifically, a decrease in bacterial groups capable of triggering these transformations such as Ruminococcaceae, Lachnospiraceae, and Blautia (all having $7 \alpha$-dehydroxylating activity) have been found in NAFLD cirrhosis fecal samples. ${ }^{39}$ Moreover, NAFLD patients show a higher ratio of hydrophobic and 
cytotoxic BA species with increased levels in the serum, urine, and liver tissue. ${ }^{40}$

Recent work has also shown that BAs also represent signaling molecules that influence metabolism in the host by binding nuclear and membrane receptors. ${ }^{41}$ At least four nuclear receptors, ligand-activating transcription factors, recognize BAs and regulate the intestinal physiology by controlling gene expression: nuclear receptor subfamily 1 group I member 2, vitamin D3 receptor, nuclear receptor subfamily 1 group I member 3, and the most studied BA receptor (also known as farnesoid $X$ receptor or FXR). The FXR participates in the crosstalk between the host and GM through the modulation of enterohepatic BA circulation, as it modulates the synthesis of BAs both in the intestine and the liver (in a tissue-dependent manner via FGF19 or SHP, respectively). ${ }^{42}$ Additionally, a protective role for FXR in NAFLD has been studied, since its activation has been known to decrease triglyceride levels and thus suppress the synthesis and uptake of fatty acids in the liver. Moreover, it has demonstrated a major role in suppressing the mucosal immune response and in modulating glucose metabolism (i.e., reducing insulin resistance and gluconeogenesis, and increasing glycogenesis). ${ }^{43}$ Activation of FXR would also protect against bacterial overgrowth, gut permeability, and bacterial translocation. ${ }^{44}$ Thus, bacterial translocation from the gut might further decrease FXR activation in the liver, leading to decreased activity of the bile salt export pump. However, contradictory results have been obtained when using FXR-deficient mice, which are resistant to diet-induced obesity. One possible explanation for these findings could be found in the role of intestinal FXR and GM in regulating this process. ${ }^{45-47}$

Conversely, three major membrane receptors are known to interact with BAs: muscarinic acetylcholine receptor M3, sphingosine-1-phosphate receptor 2, and the G-protein-coupled BA receptor 1 (also known as TGR5). TGR5 activation promotes differentiation of intestinal $\mathrm{L}$ cells, a type of enteroendocrine cell responsible for the secretion of GLPs and PYY. ${ }^{48}$ TGR5 signaling also increases colonic motility and it has been related to the anti-inflammatory response. Indeed, Tgr5 knockout mice show a constipated phenotype with a decrease in the water content of the stool, an effect mediated by the effectors 5-HT and CGRP. ${ }^{49}$ Furthermore, TGR5 activation by secondary BAs enhances energy expenditure in skeletal muscle and brown adipose tissue through increased thermogenesis. ${ }^{50,51}$

Thus, the reduction of secondary BAs ascribed to dysbiosis lowers the activation of FXR and TGR5 in the ileum, leading to bile salt accumulation, altered glucose and lipid homeostasis, gut permeability, bacterial overgrowth, and translocation, all of which contribute to liver disease progression.

\section{Endogenous Ethanol}

Ethanol is a microbial metabolite that is constantly produced by saccharolytic fermentation and microbial cross-feeding even in the absence of alcohol consumption. The amount of ethanol produced depends on the carbohydrates consumed with the diet and it has been shown that obese NASH patients have a greater abundance of ethanol-producing bacteria in the feces as well as increased levels of ethanol in the circulation and breath compared with obese or healthy controls. ${ }^{52-54}$ Previously, Cope et al demonstrated that $o b / o b$ mice have a higher concentration of alcohol in breath that could be reduced after antibiotic treatment. ${ }^{55}$ Additionally, an upregulation of the three major hepatic alcohol metabolizing pathways has been reported both in pediatric and adult NAFLD patients. ${ }^{56,57}$ Although some researchers suggested that ethanol levels are increased due to insulin-dependent impairments of alcohol dehydrogenase $(\mathrm{ADH})$ activity in the liver, recent evidence points to a role for microbiota-derived ethanol in the development of NASH. ${ }^{58,59}$

In addition to causing triglyceride accumulation in the liver, alcohol aggravates the inflammation and oxidative stress and, when it is metabolized by the $\mathrm{ADH}$, produces acetaldehyde. CYP2E1 then converts it into acetate but this pathway can be saturated followed by acetaldehyde accumulation, which is toxic even in small quantities. The damage produced could be involved in NAFLD progression through the following: (1) direct toxicity on hepatic cells, (2) impairment of gut barrier function by downregulation of tight junction expression and dissolution of the lipids in the mucin layer, therefore resulting in the translocation of bacterial products into the systemic circulation, and (3) via nuclear factor kappa B (NF-kB) signaling pathways in peripheral cells. ${ }^{60-62}$ In addition, it has been associated with changes in lipid metabolism in the liver: increased de novo lipogenesis, decreased fatty acid oxidation, and defective export of very low-density lipoprotein (VLDL) particles. $^{63,64}$ Moreover, this compound can induce an inflammatory and adaptive immune response by downregulating the expression of antimicrobial peptides in the gut. Recent studies have explored the role of $\alpha$-defensin 5 and cathelicidin, antimicrobial peptides, in the suppression of lipid accumulation and the resolution of hepatic steatosis. ${ }^{65,66}$ Future studies might confirm whether patients with NAFLD should modify their dietary patterns by replacing certain indigestible carbohydrates with others that do not increase ethanol levels and avoid ethanol-producing bacterial overgrowth.

\section{Choline/Trimethylamine}

The nutrient choline is mainly obtained from the diet being stored and used in the liver for the biogenesis of phosphatidylcholine and for maintaining the S-adenosyl methionine cycle. Choline is essential for VLDL production and its deficiency can lead to NAFLD, causing the deposition of fatty acids and cholesterol, oxidative stress, and alterations in cytokine production $^{67}$; thus, dietary choline deficiency has been linked to liver disease for a long time and is commonly used to induce NAFLD in animals. Moreover, the deletion of genes involved in choline metabolism also leads to NAFLD. ${ }^{68}$

The GM converts choline to methylamines (e.g., Escherichia coli, Desulfovibrio desulfuricans) and phosphatidylcholine, the demand for which can be increased in the context of NAFLDassociated bacterial overgrowth, lowering the availability of choline. Additionally, trimethylamine reaches the liver via portal vein, where it is oxidized to trimethylamine $\mathrm{N}$-oxide 
(TMAO) by hepatic flavin-containing monooxygenases. ${ }^{69}$ TMAO has been found to contribute to the risk for atherosclerosis by reducing reverse cholesterol transport, promoting changes in BAs, and activating the inflammatory response to mediate foam cell formation; it also contributes to other metabolic disorders such as T2D and NAFLD. ${ }^{70,71} \mathrm{~A}$ clinical study found that the severity of NAFLD was independently correlated with high serum levels of TMAO in Chinese adults. ${ }^{72}$ Another study reported a correlation between serum levels of TMAO and the body mass index, also suggesting that a specific cut-off of TMAO levels could help to assess the risk for NAFLD. ${ }^{73}$ Moreover, animal studies have shown that TMAO supplementation in HFD mice induces impaired glucose tolerance, obstructs the hepatic insulin signaling, and triggers adipose tissue inflammation. Furthermore, the inhibition of trimethylamine production revealed favorable effects in the study of cardiometabolic diseases. ${ }^{74}$ Therefore, future studies are expected to explore and confirm the effects of trimethylamine on NAFLD.

\section{Microbiome-Induced Liver Inflammation}

Current understanding of the pathophysiology of liver diseases relies on proinflammatory changes that take place in the host. Low-grade chronic inflammation is a hallmark of metabolic disorders such as obesity, T2D, and NAFLD, which contribute to patient outcomes within (liver cirrhosis) and outside the liver (atherosclerosis and cardiovascular complications). Several studies have revealed increased inflammatory molecules such as cytokines, acute-phase proteins, and adhesion molecules in the circulation of NASH patients. ${ }^{75-77}$ This metabolic inflammation can be seen as a sterile process, as noninfectious factors, such as lipids, drive a low-grade inflammatory state via toll-like receptor (TLR) 4 in peripheral blood monocytes. ${ }^{78}$ Moreover, lipotoxicity in the liver, muscle, or adipose tissue can trigger off a metabolic dysregulation leading to endoplasmic reticulum and oxidative stress, key drivers of the inflammatory response. $^{79,80}$ In a similar way, hypoxia in adipose tissue triggers inflammatory pathways while suppressing antiinflammatory adipokine production. ${ }^{81}$

Conversely, dysbiosis and increased intestinal permeability facilitate the translocation of microorganisms and their subproducts including cell-wall components (endotoxins or B-glucan) or DNA (-Fig. 2). Any antigen that crosses the gut barrier, generated either from pathogenic microorganisms or directly from the diet, even small quantities of PAMPs (lipopolysaccharides [LPS], peptidoglycans or flagellin, ADPheptose, and lipoteichoic acid), would lead to a proinflammatory response by innate and adaptive immune cells. ${ }^{82-84}$ These molecules can be detected by tissue-resident dendritic cells and macrophages via TLRs and nod-like receptors (NLRs), which become activated and trigger the production of inflammatory cytokines and chemokines after activation of NF-kB. ${ }^{13,85}$ This cascade of events influences hepatic stellate cell activation and causes bone-marrow-derived cells to infiltrate the injured liver. ${ }^{86}$ Moreover, immune cells may be primed in the gut and migrate to other organs, such as the liver and the adipose tissue, to modulate metabolic inflammation. ${ }^{87}$

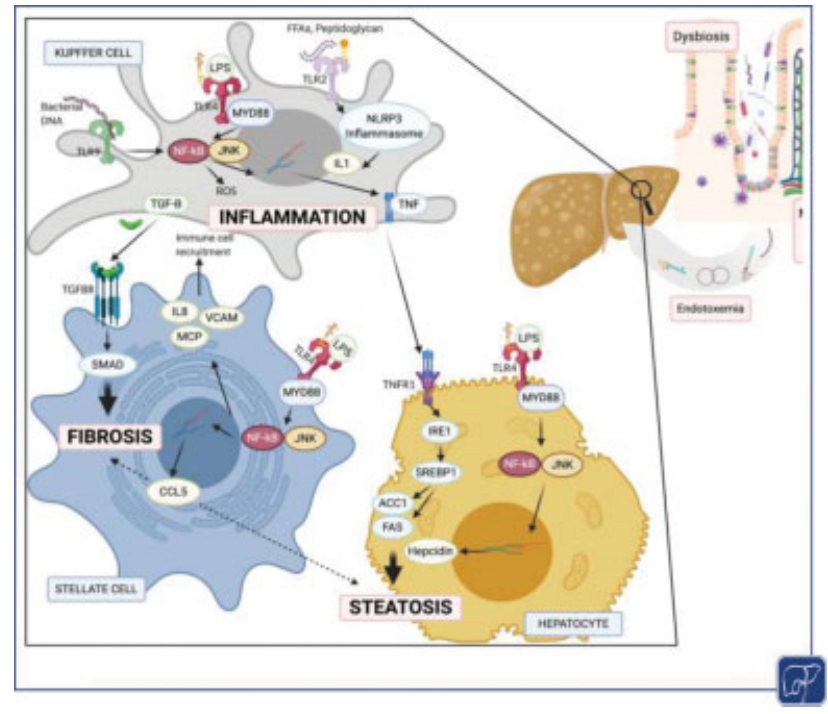

Fig. 2 The mechanism of liver cell damage in NAFLD progression induced by endotoxemia. Following dysbiosis, microbiota-derived products reach the liver through the portal vein. TLR signaling and communication between different cell types (Kupffer cells, hepatic stellate cells, and hepatocytes) sense these products and trigger not only cytokine production and inflammatory responses, but also lipid accumulation and fibrosis, key events in NAFLD progression. NAFLD, nonalcoholic fatty liver disease; TLR, toll-like receptor.

Recently, several studies have suggested a major role for endotoxemia as a driver of metabolic diseases; it has been associated with an increased risk of obesity and has been suggested to promote T2D. ${ }^{88,89}$ Of note, injection of endotoxin into mice resulted in systemic and adipose tissue inflammation, along with insulin resistance, a dysregulation that could be prevented by antibiotic treatment in diet- or genetic-induced obese mice. ${ }^{90,91}$ In humans, plasmatic endotoxin levels correlate with the degree of liver inflammation and fibrosis but also with high energy intake, revealing the impact of the diet in endotoxemia. ${ }^{92,93}$ Similarly, HFD administration resulted in the expansion of LPS-containing bacteria and up to a $70 \%$ increase in endotoxin plasma levels. ${ }^{94}$ Conversely, the administration of a prebiotic (oligofructose) or functional bacterial changes after calorie restriction reduces endotoxemia, further confirming the role of the GM in this process. ${ }^{95,96}$ Although some bacterial LPS subtypes have higher immunogenicity than others, the exact contribution of every bacterial strain to the metabolic phenotype remains elusive. ${ }^{97}$ In this regard, an opportunistic pathogen isolated from an obese human recapitulated the metabolic disorder in germ-free mice. ${ }^{98}$ Similarly, peptidoglycan-based cell-wall compounds can affect inflammatory responses through the sensor NOD1, which promotes the release of interleukin (IL)-17A from the mouse intestine but also contributes to insulin resistance. Of note, HFD-fed mice showed levels of NOD1 activators in the circulation. ${ }^{99}$ Moreover, NOD1 ligands induced inflammation in the liver and the adipose tissue while NOD1-deficient mice are protected from obesity-induced inflammation and showed reduced infiltration of proinflammatory macrophages. ${ }^{100}$

Various bacterial metabolites have been reported to play a role in the exacerbation of the inflammatory phenotype. 
TMAO levels correlate with atherosclerosis and cardiovascular complications, glycemic control and NAFLD, being a driver of inflammation and platelet activation..$^{72,101,102}$ On the other hand, enhanced SCFA production has been reported to improve glucose homeostasis and to exert anti-inflammatory effects inducing regulatory T cells. ${ }^{103,104}$

\section{How the Microbiome Impacts on Gut-Barrier Function}

The molecular mechanisms driving intestinal permeability alterations and their regulation by the host, microbiota, and lifestyle-related factors represent still an open question and require further elucidation. Most studies have only assessed epithelial tight junction expression, underestimating the influence of the supplementary barriers that prevent bacterial translocation. Also, neither the mucus abundance nor the production of immunoglobulins or antimicrobial peptides is normally tested, leading to the need for a better understanding of these additional processes and their regulation.

\section{Mucus Layer}

The intestinal barrier is strengthened by the presence of mucins, which are highly glycosylated proteins that form a layer that plays three major roles: it prevents a direct connection between the microbiota and the epithelial cells, it provides support for bacteria to avoid its elimination during the intestinal peristaltic movements, and it is also used as a nutrient for some bacteria. ${ }^{105}$ In the colon, the external layer offers nutrients for bacteria, and the internal layer confers protection to the host, being sterilized by the production of antimicrobial peptides and other proteins such as Lypd8 or ZG16. ${ }^{106,107}$ An in vivo experiment showed that the composition of the mucus layer is commanded by the microbiota since after colonization, germ-free mice develop a mucus layer similar to the donor. ${ }^{108}$ In fact, further experiments have shown that the GM can alter the intestinal barrier by degrading mucus or by inhibiting the production of mucus, both of which result in increased permeability of the epithelium. ${ }^{109}$ Mice with a chronic or intermittent-fiberdeprived diet showed changes in the microbiota that favor the overgrowth of mucin-degrading bacteria. Consequently, the mucus layer permeability and susceptibility to infections were increased, a state reverted after microbiota transplantation from control mice. ${ }^{110,111}$ Moreover, diet-induced changes in the balance between Bacteroides and Firmicutes can alter the glycosylation of mucins. ${ }^{112}$

However, the mucosal immune milieu also shapes the microbiota. During homeostasis, the commensal microbiota is sensed by the dendritic cells in Peyer's patches that, via the Mincle-SYK signaling pathway, produce IL-6 and IL-23 and stimulate intestinal T cells, which in turn produce IL-17 and IL-22. ${ }^{113}$ Mucosal immune cells (such as RORyt-dependent TH17 cells) prevent bacterial translocation and systemic inflammation through the production of REG3 $\gamma$ and other antimicrobial peptides. ${ }^{114,115}$ Martínez-López et al showed that mice with genetic disruption of the Mincle-SYK pathway presented liver inflammation and impaired lipid metabolism with accumulation of diacylglycerides and fatty acids in the liver. ${ }^{113}$ Controversially, recent data showed that loss of mucin-2 protected mice from NAFLD and the features of metabolic syndrome possibly by activating the mucosal immune system. ${ }^{116}$

\section{Epithelial Barrier}

The intestinal epithelium forms a tightly sealed physical barrier that separates the host from the contents of the gut, restricting access to toxins, antigens, and enteric flora to the circulation, while nutrients are selectively absorbed. ${ }^{109}$ This barrier comprises enterocytes, goblet cells, and enterochromaffin cells that are bound to each other by transmembrane proteins including desmosomes, adherens junctions, and tight junctions granting them a physical sealing. ${ }^{117}$ It also has immunological properties that help to maintain homeostasis between the microbiota and the host through a tolerogenic immune response. This equilibrium is achieved by pattern recognition receptors (PRRs), secretion of immunoglobulin $\mathrm{A}$ and antimicrobial peptides, and an immune environment formed by $\mathrm{CD} 103^{+}$ dendritic cells, regulatory T cells, and cytokines (IL-33, IL-10, and transforming growth factor beta). ${ }^{118}$

Recently, the connection between dysbiosis, barrier permeability, liver damage, and metabolic abnormalities has been established. Morphologically, obese patients display jejunal villus hyperplasia that leads to a greater surface area of exchange with alterations in the immune compartment. ${ }^{119}$ Indeed, in a cohort of 39 pediatric NAFLD patients, Giorgio and colleagues showed, using a lactulose/mannitol test, the existence of intestinal permeability, which correlated with the severity of liver disease. ${ }^{120}$ In another study, Miele et al reported evidence of intestinal permeability in patients with NAFLD, which correlated with small intestinal bacterial overgrowth (SIBO), decreased expression of ZO-1, and the severity of steatosis. ${ }^{121}$ Accordingly, studies in mice fed high-fat or choline-deficient diets showed higher intestinal permeability, while they were protected in the absence of microbiota after antibiotic treatment. ${ }^{122}$ It has also been demonstrated that a nutrition rich in fat can influence intestinal permeability and thus inflammation. Additionally, HFD resulted in a depletion of eosinophils in the small intestine, driving a greater paracellular permeability. ${ }^{123}$ Consistently, obese patients showed an increased permeability in the jejunum after a lipid challenge and a higher density of epithelial CD8 $+\mathrm{T}$ cells, which migrate from the lamina propria to the epithelium. ${ }^{124,125}$ In this setting, a decrease in regulatory $T$ cells with an increase in interferon- $\gamma$ producing $\mathrm{TH} 1$ cells has also been found. ${ }^{126}$ In vitro and in vivo experiments have shown that LPS can cross the epithelial barrier via the transcellular path by chylomicrons. ${ }^{127,128}$

It is not clear, however, if the disruption of the barrier is a cause or consequence of endotoxin exposure. Endotoxins from the outer membrane of gram-negative bacteria have been found to increase tight junction permeability by upregulating TLR4 expression. ${ }^{129}$ A recent study using mice deficient in junctional adhesion molecule (JAM)-A on a high-fat highfructose diet demonstrated increased bacterial translocation leading to liver inflammation and NASH. Also, NASH patients showed a decrease in JAM-A in colonic biopsies together with 
increased mucosal inflammation. ${ }^{130}$ By contrast, the tryptophan bacterial-produced metabolite indole propionic acid has shown to play a role in maintaining intestinal epithelial homeostasis, improving gut dysbiosis, reducing endotoxin leakage, and the production of proinflammatory cytokines in HFD-fed mice. ${ }^{131}$

Nevertheless, it remains to be established whether the capacity to cross the barrier after HFD exposure is only due to an increased leakiness of the epithelium caused by downregulation of tight junction proteins or if it is an acquired function of the microbiota due to an enrichment in pathobionts.

\section{Vascular Barrier}

The gut vascular barrier (GVB) has been recently described as an intestinal barrier in addition to the epithelium, which actively prevents systemic bacterial dissemination from the gut, even in the case of mucoepithelial dysfunction. This barrier is anatomically located below the epithelial cell layer and is composed mainly of intestinal endothelial cells, sharing many characteristics with other vascular barriers, in particular the blood-brain barrier. ${ }^{132}$ Indeed, endothelial cells forming the GVB harbor intercellular junctional complexes that reduce the paracellular trafficking and are in close contact with pericytes and enteric glial cells. Gut vascular endothelial cells present fenestrae covered by a diaphragm composed by the plasmalemmalvesicle-associated protein 1 (PV-1) that determines pore size. Increased detection of PV-1 by the MECA antibody clone has been positively associated with and increased endothelial permeability reflecting a dysfunctional GVB. ${ }^{132}$ Some enteric pathogens, such as Salmonella typhimurium, have developed tactics to penetrate the GVB and reach peripheral tissues by interfering with B-catenin activation in endothelial cells via Spi2 (Salmonella pathogenicity island 2). ${ }^{133}$ In a healthy state, the GVB controls the selective translocation of immune cells and antigens across the blood endothelial cells, allowing only small molecules to extravasate from intestinal capillaries. By contrast, GVB disruption is responsible for the accessibility of bacteria and their subproducts to the portal-venous circulation, and their dissemination to the liver, contributing to the development of hepatic diseases. Therefore, the GVB plays a key role along the gut-liver axis ${ }^{134}$ in both healthy and pathological states.

Recent data showed that changes in GM composition occurring during NASH pathogenesis are directly responsible for the disruption of both the gut epithelial and vascular barriers, being indeed a fundamental prerequisite for the development of the disease..$^{20,135}$ Genetic and pharmacological treatments sealing the GVB have been shown to block the accumulation of lipids in the liver and to exert therapeutic effects in NAFLD/NASH diet-induced mouse models. Moreover, pathological bacterial translocation is associated with GVB disruption in experimental models of cirrhosis, independently of portal hypertension and the lymphatic route. ${ }^{136}$ In this way, it has been shown that part of the beneficial effects of FXR agonism for NASH and cirrhosis models might be driven by the sealing of the GVB through the activation the WNT/B-catenin pathway. ${ }^{20,136}$

\section{Role in Liver Fibrosis Development}

The progression of NAFLD in terms of NASH, liver cirrhosis, and hepatocellular carcinoma is mostly driven by inflammatory events, which can impact the amount of fibrosis, defining the long-term prognosis of the liver disease. ${ }^{137}$ Different alterations of the GM such as SIBO and dysbiosis have been associated with liver cirrhosis and treatment with nonabsorbable antibiotics (e.g., rifaximin) is recommended in certain cases. ${ }^{138}$ Also, specific changes in the microbiota and its metabolic function have been associated with progression of the disease. Boursier et al identified, in a cohort of 57 biopsy-proven NAFLD patients, that the abundance of Bacteroides was associated with NASH and Ruminococcus with significant fibrosis. ${ }^{139}$ Recently, it was reported that the existence of gut microbiome signatures was able to detect either advanced fibrosis, characterized by an increased abundance of E. coli and Bacteroides vulgatus, or cirrhosis. $^{8,19}$ Moreover, all experimental models of fibrosis result in dysbiosis and increased permeability, whereas the use of antibiotics in a choline-deficient, L-amino acid-defined (CDAA)-fed rat model decreased hepatic stellate cell activation and the severity of fibrosis. ${ }^{140,141}$ The consumption of fructose can also exert hepatotoxic effects through its conversion to toxic metabolites by the microbiota. Indeed, it has been associated with hepatic fibrosis in NAFLD patients, but also with dysbiosis and endotoxemia. $^{142,143}$

These events lead to the translocation of microbe-associated molecular patterns, which are recognized by immune receptors in intestinal cells, but also in liver cells. Fibrogenesis can then be triggered by direct activation of these receptors on hepatic stellate cells or indirectly by targeting hepatocytes and Kupffer cells where an inflammatory cascade starts ultimately leading to liver fibrosis promotion and progression. ${ }^{144,145}$ In fact, Kupffer cells are more sensitive to LPS than hepatocytes, and activation of TLRs has been shown to contribute to the fibrotic process through NLR family pyrin domain-containing 3 (NLRP3) inflammasomes. ${ }^{146}$ Accordingly, mice with genetic ablations of Tlr2, Tlr4, Tlr9, and Nlrp3 are protected from experimental liver fibrosis. ${ }^{147}$ However, a greater effect is suggested to be directly exerted on hepatic stellate cells, which express TLR4 even in a quiescent state. Available data suggest that TLR4-MyD88-NF-kB mediates fibrosis by upregulating cytokine production and a-SMA, TIMP1, and TGF-B expression. Moreover, continued activation of TLR4 has been shown to sensitize quiescent hepatic stellate cells for activation via downregulation of Bambi. ${ }^{148}$ Other receptors, such as NOD-like and antifungal pattern-recognition receptors have been related to fibrosis. NOD1 stimulation can activate the NF-kB and MAPK pathway, inducing the production of CXCL1 and CCL5, further contributing to processes such as wound healing and fibrogenesis. ${ }^{149}$ Lastly, it was proposed a role for STING in liver fibrogenesis which, beyond regulating insulin sensitivity, enhances macrophage proinflammatory activation leading to fibrosis via paracrine mechanisms in hepatic stellate cells. $^{150}$

Finally, and given the endotoxemia observed in NAFLD patients, it is plausible that fibrosis develops as a direct consequence of dysbiosis. ${ }^{151}$ The role of endogenous ethanol 
in fibrosis is also being studied. Also, the expression of CYP2E1 correlates with the level of ethanol and is linked to the levels of oxidative stress, a potent profibrotic mechanism. Accordingly, a study by Zong et al reported increased expression of CYP2E1 in NASH patients. ${ }^{152}$

\section{Final Remarks and Future Prospects}

This review has emphasized the connection between the liver and the gut, which consist of a complex balance of microbiota, its metabolites, and immunity, in the context of NAFLD. Addressing metagenomics is surrounded by several limitations in computational analysis, statistical assessments, standardization, and validation due to the vast variability of the cohorts themselves, experimental designs, and bioinformatics workflows, which we attempted to solve to reach conclusions. Here, we showed strong associations between microbiota changes and altered host metabolism. - Table 2 summarizes human studies that show a link between NAFLD and dysbiosis. However, it is still uncertain if liver disease state stimulates changes in the microbiota or if the microbiota exacerbates fibrotic and inflammatory progression. Indeed, much of this knowledge comes from cross-sectional or case-control association studies from which potential relationships can be demonstrated; however, it is almost impossible to isolate this association from secondary effects inherent to the condition and evidence toward causality is often missing. Additionally, an optimal healthy microbiota is unique for each individual, making the selection of control cohorts also a great source of bias since the microbiota composition is dynamic and influenced by lifestyle, medical history, and host genetics. Thus, matching cohorts based on age and sex is sometimes insufficient, and the differences detected in these studies could be owed to confounding factors. Regardless, it seems unlikely that single microbiota signatures can define the whole spectrum of NAFLD phenotypes. In general, there is a lack of reproducibility between cohorts, with an absence of a mechanistic explanation for dysbiosis on NAFLD. In this concern, discrepancies in studies assessing GM may also arise from technical issues: sample collection, storage, primer selection, and analysis techniques. Therefore, unified research standards should be established, and efforts to address sources of variation, such as the Microbiome Quality Control Project, are needed. ${ }^{153}$

Researchers have attempted to avoid some of these issues by performing twin studies, analyzing the heritability of hepatic steatosis and fibrosis. However, the sample size required for these studies to reach proper statistical power is usually challenging. ${ }^{154,155}$ Nevertheless, ongoing longitudinal studies will help to examine the role of the gut bacterial communities in the development of complex metabolic disorders. As with humans, data extracted from animal models must be carefully interpreted. First, the rodent and human microbiota present differences. Second, some models, such as germ-free, gnotobiotic, or specific pathogen-free mice can be useful in the understanding of the impact of some bacteria on the experimental hypothesis. However, germ-free mice have an immature immune system with GVB damage, the exact composition of the gnotobiotic mice microbiota is still unknown, and specific pathogen-free mice lack strains that are potentially pathogenic. Indeed, it has been reported that the complete absence of microbiota may confer protection or exacerbation of liver diseases, possible due to an accumulation of constitutive androstane receptor ligands and a more efficient xenobiotic metabolism. ${ }^{156}$ Antibiotic treatment to create microbiota-free mice has also been used. However, they can create resistance and overgrowth of certain strains, which is why the use of several models to address with precision the role of microbiota has been recommended.

The consequences of a disrupted gut-liver axis include altered microbiota, gut barrier damage, and reduced intestinal FXR signaling due to impaired BA metabolism. These events drive functional changes that promote the exposure of liver innate immune cells to bacterial subproducts and metabolites, resulting in liver inflammation and metabolic disturbances. Promising therapeutic approaches are underway, which can be classified in the way they target the gut-liver axis (-Table 3 ). One approach is based on the use of bacteria to alter the composition of the GM, such as FMT (fecal microbiota transplantation), although there are no published results in patients with NASH to date, and there are some concerns about its safety and efficacy alone without lifestyle interventions. Also, the effect of probiotics, prebiotics, or synbiotics has been under investigation, with trials showing reductions in liver enzymes, steatosis, and liver stiffness; however, no recommendation can be made yet due to the variability of the studies. Besides, some studies have revealed the potential use of engineered bacteria (e.g., Lactobacillus reuteri producing IL-22) to restore homeostasis to the gut-liver axis. ${ }^{157,158}$ Other approach under study is to directly target the microbiota either with antibiotics, currently nonspecific and with potential side effects, or with bacteriophages, viruses that can defeat specific species of bacteria. Another approach that has gained attention lately is the supplementation with microbe-derived products (so-called postbiotics) to replace metabolic activities lost due to dysbiosis. Other interventions relay on pharmacological modulation of gut peptides, such as GLP-1, or BA pathway.

Finally, an active area of research is the profiling of the microbiome by multiomics analysis, which is expected to provide markers of liver damage and disease progression, predicting hospitalizations and complications. However, we must be aware of the complex relationship between the host, the microbiota, and the external environment and how the limitations of each study impact the observations. In this regard, there are still some pending issues to address in the future: (1) to establish specific alterations in the composition of the microbiota and microbial functions that take place in NAFLD patients. To date, an accurate definition of a healthy microbiota and the precise associations between GM and NAFLD is still lacking. (2) Despite a plethora of scientific evidence demonstrating that the GM is a contributing pathogenic factor in NAFLD, there is still the need to demonstrate the molecular mechanism involving the gut-liver axis underlying the pathogenesis of NAFLD, thus confirming a direct causal role of the GM alterations in the development of metabolic and liver dysfunction. (3) In the future, noninvasive serum biomarkers and individualized treatments targeting the 
Table 2 List of human studies that correlated changes in intestinal microbiome to NAFLD/NASH

\begin{tabular}{|c|c|c|c|c|c|}
\hline Population & Method & BMI & NAFLD diagnosis & Main outcome & Ref. \\
\hline $\begin{array}{l}26 \text { Controls, } 11 \text { obese, } \\
13 \text { NAFLD }\end{array}$ & $\begin{array}{l}16 S \text { rRNA, } \\
\text { shotgun }\end{array}$ & Obese & $\begin{array}{l}\text { Ultrasonography } \\
\text { or biopsy }\end{array}$ & $\begin{array}{l}\text { Obese children with NAFLD showed increased } \\
\text { Gammaproteobacteria, Epsilonproteobacteria, } \\
\text { and Prevotella. }\end{array}$ & $\begin{array}{l}\text { Michail et al } \\
2015^{168}\end{array}$ \\
\hline 30 NAFLD vs. 30 controls & Pyrosequencing & Obese & $\begin{array}{l}\text { Ultrasonography } \\
\text { and blood test }\end{array}$ & $\begin{array}{l}\text { Increased Ruminococcaceae, reduced } \\
\text { Lactobacillaceae and Lachnospiraceae. }\end{array}$ & $\begin{array}{l}\text { Raman et al } \\
2013^{169}\end{array}$ \\
\hline $\begin{array}{l}16 \text { Controls, } 25 \text { obese, } \\
22 \mathrm{NASH}\end{array}$ & Pyrosequencing & Obese & Biopsy & $\begin{array}{l}\text { Obese and NASH children versus healthy } \\
\text { controls had increased Bacteroidetes and } \\
\text { Prevotella. }\end{array}$ & $\begin{array}{l}\text { Zhu et al } \\
2013^{53}\end{array}$ \\
\hline 16 NASH vs. 22 controls & Pyrosequencing & Overweight & Biopsy & $\begin{array}{l}\text { Decreased Firmicutes. No changes in } \\
\text { Bacteroidetes. }\end{array}$ & $\begin{array}{l}\text { Wong et al } \\
2013^{170}\end{array}$ \\
\hline 37 NASH vs. 20 NAFLD & $16 \mathrm{~S}$ rRNA & Obese & Biopsy & $\begin{array}{l}\text { Increased Bacteroides in NASH patients. } \\
\text { Ruminococcus abundance correlated } \\
\text { with fibrosis stage. }\end{array}$ & $\begin{array}{l}\text { Boursier et al } \\
2016^{139}\end{array}$ \\
\hline 98 NAFLD, 105 relatives & $16 \mathrm{~S}$ rRNA & Obese & Biopsy & $\begin{array}{l}\text { Increased gram-negative in advanced fibrosis. } \\
\text { Streptococcus was enriched in NAFLD } \\
\text { patients. A signature with } 27 \text { bacterial groups } \\
\text { allowed the identification of NAFLD cirrhosis. }\end{array}$ & $\begin{array}{l}\text { Caussy et al } \\
2019^{8}\end{array}$ \\
\hline 105 Obese women & Shotgun & Obese & Biopsy & $\begin{array}{l}\text { Morbid obese women with steatosis had } \\
\text { fewer Lachnospiraceae and Ruminococcaceae. } \\
\text { Escherichia and Bacteroides were associated } \\
\text { with insulin resistance. }\end{array}$ & $\begin{array}{l}\text { Hoyles et al } \\
2018^{171}\end{array}$ \\
\hline 25 NAFLD vs. 22 controls & $16 \mathrm{~S}$ rRNA & Overweight & Biopsy & $\begin{array}{l}\text { Lower diversity with increased Blautia and } \\
\text { Lachnospiraceae, and decreased Prevotella. }\end{array}$ & $\begin{array}{l}\text { Shen et al } \\
2017^{172}\end{array}$ \\
\hline $\begin{array}{l}123 \text { NAFLD-mild fibrosis, } \\
28 \text { NAFLD advanced fibrosis }\end{array}$ & Shotgun & Obese & Biopsy & $\begin{array}{l}\text { A decrease in Firmicutes and an increase of } \\
\text { Proteobacteria in NASH patients with } \\
\text { advanced fibrosis. Increased prevalence of } \\
\text { gram-negative taxa. }\end{array}$ & $\begin{array}{l}\text { Loomba et al } \\
2017^{19}\end{array}$ \\
\hline $\begin{array}{l}54 \text { Controls, } \\
61 \text { NAFLD or obese }\end{array}$ & $16 \mathrm{~S}$ rRNA & Obese & $\begin{array}{l}\text { Ultrasonography } \\
\text { and biopsy }\end{array}$ & $\begin{array}{l}\text { No differences observed among NAFL, NASH, } \\
\text { and obese children. NASH showed increased } \\
\text { Ruminococcus, Blautia, and Dorea compared } \\
\text { with controls. }\end{array}$ & $\begin{array}{l}\text { Del Chierico } \\
\text { et al } 2017^{173}\end{array}$ \\
\hline $\begin{array}{l}17 \text { Controls vs. } 11 \text { steatosis } \\
\text { vs. } 22 \mathrm{NASH}\end{array}$ & qPCR & Obese & Biopsy & $\begin{array}{l}\text { Lower Bacteroidetes in NASH patients } \\
\text { (adjusted by BMI and fat intake). }\end{array}$ & $\begin{array}{l}\text { Mouzaki et al } \\
2013^{174}\end{array}$ \\
\hline $\begin{array}{l}32 \text { NASH vs. } 181 \\
\text { non-NASH cirrhotic }\end{array}$ & Pyrosequencing & Obese & Blood test & $\begin{array}{l}\text { Cirrhotic NASH had increased Porphyromo- } \\
\text { nadaceae and Bacteroidaceae; reduced } \\
\text { Veillonellaceae. }\end{array}$ & $\begin{array}{l}\text { Bajaj et al } \\
2014^{175}\end{array}$ \\
\hline 43 NAFLD vs. 83 controls & Pyrosequencing & Lean & Ultrasonography & $\begin{array}{l}\text { Increased Bacteroidetes and decreased } \\
\text { Firmicutes in nonobese NAFLD patients. }\end{array}$ & $\begin{array}{l}\text { Wang et al } \\
2016^{176}\end{array}$ \\
\hline 30 NAFLD vs. 37 controls & Pyrosequencing & Overweight & Ultrasonography & $\begin{array}{l}\text { Differences only at family or genus levels. } \\
\text { Increased Lactobacillaceae and Veillonellaceae. } \\
\text { Central obesity and insulin metabolism related } \\
\text { to changes in microbiota. }\end{array}$ & Li et al $2018^{177}$ \\
\hline 53 NAFLD vs. 32 controls & 16S rRNA & Overweight & $\begin{array}{l}\text { Ultrasonography } \\
\text { or biopsy }\end{array}$ & $\begin{array}{l}\text { Within Firmicutes, increased Peptostreptococca- } \\
\text { ceae, Lactobacillaceae, and Streptococcus with } \\
\text { decreased Ruminococcaceae. In Bacteroidetes, } \\
\text { decreased Porphyromonadaceae and Prevotella. }\end{array}$ & $\begin{array}{l}\text { Jiang et al } \\
2015^{178}\end{array}$ \\
\hline $\begin{array}{l}28 \text { Controls vs. } 15 \text { steatosis } \\
\text { vs. } 24 \mathrm{NASH}\end{array}$ & $16 \mathrm{~S}$ rRNA & Obese & Biopsy & $\begin{array}{l}\text { No differences between simple steatosis and } \\
\text { NASH. Increased Lactobacillaceae and } \\
\text { decreased Ruminococcus, Faecalibacterium, } \\
\text { and Coprococcus in NAFLD compared with } \\
\text { controls. }\end{array}$ & $\begin{array}{l}\text { Da Silva } \\
\text { et al } 2018^{179}\end{array}$ \\
\hline 90 NAFLD vs. 21 controls & $16 \mathrm{~S}$ rRNA & Obese & $\begin{array}{l}\text { Ultrasonography } \\
\text { or biopsy }\end{array}$ & $\begin{array}{l}\text { Decreased Bacteroidetes and } \\
\text { Ruminococcaceae, increased abundance of } \\
\text { Lactobacillaceae, Veillonellaceae, and Dorea in } \\
\text { NAFLD patients. }\end{array}$ & $\begin{array}{l}\text { Demir et al } \\
2020^{180}\end{array}$ \\
\hline
\end{tabular}

Abbreviations: BMI, body mass index; NAFLD, nonalcoholic fatty liver disease; NASH, nonalcoholic steatohepatitis; qPCR, quantitative polymerase chain reaction; rRNA, ribosomal ribonucleic acid. 
Table 3 Selected studies targeting the gut-liver axis in NAFLD

\begin{tabular}{|c|c|c|c|c|c|c|}
\hline $\begin{array}{l}\text { Place of } \\
\text { action }\end{array}$ & Type & Subjects & Intervention & Mechanism & Outcomes & References \\
\hline \multirow[t]{7}{*}{$\begin{array}{l}\text { Intestinal } \\
\text { microbiome }\end{array}$} & \multirow[t]{2}{*}{$\begin{array}{l}\text { Nonabsorbable } \\
\text { antibiotics }\end{array}$} & $\begin{array}{l}n=50 \text { patients } \\
\text { with } \mathrm{NASH}\end{array}$ & $\begin{array}{l}\text { Randomized, double- } \\
\text { blind study. Rifaximin } \\
1,100 \mathrm{mg} / \mathrm{d} \text { for } 6 \\
\text { months }\end{array}$ & \multirow{2}{*}{$\begin{array}{l}\text { Bactericidal effect, } \\
\text { reduces endotoxin } \\
\text { levels and has } \\
\text { anti-inflammatory } \\
\text { action. }\end{array}$} & $\begin{array}{l}\text { Reduction of serum } \\
\text { endotoxin, proinflam- } \\
\text { matory cytokines, and } \\
\text { NAFLD-liver fat score. }\end{array}$ & NCT02884037 \\
\hline & & $\begin{array}{l}n=15 \text { patients } \\
\text { with } \mathrm{NASH}\end{array}$ & $\begin{array}{l}\text { Single-arm study. } \\
\text { Rifaximin } 800 \mathrm{mg} / \mathrm{d} \text { for } \\
6 \text { weeks plus } 6 \text { weeks } \\
\text { follow-up. }\end{array}$ & & No beneficial effect. & NCT01355575 \\
\hline & \multirow[t]{2}{*}{ FMT } & $\begin{array}{l}n=20 \text { patients } \\
\text { with NAFLD }\end{array}$ & $\begin{array}{l}\text { Randomized, double- } \\
\text { blind study. Allogenic or } \\
\text { autologous infusion of } \\
\text { feces at } 0,3 \text {, and } \\
6 \text { weeks by gastroscopy. }\end{array}$ & \multirow[t]{2}{*}{$\begin{array}{l}\text { Restore healthy } \\
\text { microbiome } \\
\text { composition. }\end{array}$} & Ongoing & NCT04465032 \\
\hline & & $\begin{array}{l}n=15 \text { patients } \\
\text { with } \mathrm{NASH}\end{array}$ & $\begin{array}{l}\text { Single-arm study. One } \\
\text { allogenic infusion by } \\
\text { gastroscopy plus } \\
72 \text { weeks follow-up. }\end{array}$ & & Ongoing & NCT03803540 \\
\hline & Probiotics & $\begin{array}{l}n=44 \text { obese } \\
\text { pediatric patients } \\
\text { with NAFLD }\end{array}$ & $\begin{array}{l}\text { Randomized, } \\
\text { double-blind study. Two } \\
\text { sachets/d VSL\#3 for } \\
4 \text { months. }\end{array}$ & $\begin{array}{l}\text { Restoration of normal } \\
\text { gut flora. }\end{array}$ & $\begin{array}{l}\text { Decrease in BMI and } \\
\text { increase in GLP-1. }\end{array}$ & NCT01650025 \\
\hline & Prebiotics & $\begin{array}{l}n=14 \text { patients } \\
\text { with } \mathrm{NASH}\end{array}$ & $\begin{array}{l}\text { Randomized, } \\
\text { single-blind study. } \\
\text { Oligofructose for } \\
9 \text { months vs. placebo. }\end{array}$ & $\begin{array}{l}\text { Increase in Bifidobacte- } \\
\text { rium and decrease in } \\
\text { Clostridium cluster XI } \\
\text { and I. }\end{array}$ & $\begin{array}{l}\text { Improve in liver } \\
\text { steatosis and NAS score } \\
\text { independently of } \\
\text { weight loss. }\end{array}$ & NCT03184376 \\
\hline & Synbiotics & $\begin{array}{l}n=104 \text { patients } \\
\text { with NAFLD }\end{array}$ & $\begin{array}{l}\text { Randomized, double- } \\
\text { blind study. Fructo-oli- } \\
\text { gosaccharides } 8 \mathrm{~g} \text { plus } \\
\text { Bifidobacterium animalis } \\
\text { subsp. lactis BB-12 } 1 \\
\text { capsule/d for } 1 \text { year. }\end{array}$ & $\begin{array}{l}\text { Reduce dysbiosis by } \\
\text { promoting survival and } \\
\text { colonization of healthy } \\
\text { microbiota. }\end{array}$ & $\begin{array}{l}\text { No reduction in fat or } \\
\text { markers of liver fibrosis } \\
\text { was observed. }\end{array}$ & NCT01680640 \\
\hline \multirow[t]{2}{*}{$\begin{array}{l}\text { Intestinal } \\
\text { content }\end{array}$} & $\begin{array}{l}\text { Carbon } \\
\text { nanoparticles }\end{array}$ & $\begin{array}{l}n=70 \text { patients } \\
\text { with } \mathrm{NASH}\end{array}$ & $\begin{array}{l}\text { Randomized, } \\
\text { double-blind study. } \\
\text { Yaq-001 } 8 \mathrm{~g} / \mathrm{d} \text { vs. } \\
\text { placebo. }\end{array}$ & $\begin{array}{l}\text { Carbon particles adsorb } \\
\text { bacterial toxins from } \\
\text { the intestine. }\end{array}$ & Ongoing & NCT03962608 \\
\hline & $\begin{array}{l}\text { Hydrogel } \\
\text { technology }\end{array}$ & $\begin{array}{l}n=300 \text { obese } \\
\text { patients with/ } \\
\text { without T2D }\end{array}$ & $\begin{array}{l}\text { Randomized, double- } \\
\text { blind study. Gelesis } 200 \\
\text { vs. placebo. }\end{array}$ & $\begin{array}{l}\text { Modified cellulose } \\
\text { mimicking natural fibers } \\
\text { absorbs water in the } \\
\text { intestine and increases } \\
\text { satiety. }\end{array}$ & Ongoing & NCT03058029 \\
\hline \multirow[t]{2}{*}{$\begin{array}{l}\text { Intestinal } \\
\text { mucosa }\end{array}$} & Postbiotics & $\begin{array}{l}n=60 \text { overweight } \\
\text { adults }\end{array}$ & $\begin{array}{l}\text { Randomized, double- } \\
\text { blind study. Inulin-pro- } \\
\text { pionate ester vs. inulin } \\
\text { alone for } 24 \text { weeks. }\end{array}$ & $\begin{array}{l}\text { SCFAs stimulate the } \\
\text { release of anorectic gut } \\
\text { hormones. }\end{array}$ & $\begin{array}{l}\text { Reduced weight } \\
\text { gain, liver fat, and } \\
\text { deterioration of insulin } \\
\text { sensitivity. }\end{array}$ & NCT00750438 \\
\hline & $\begin{array}{l}\text { Duodenal } \\
\text { mucosal } \\
\text { resurfacing }\end{array}$ & $\begin{array}{l}n=60 \text { patients } \\
\text { with } T 2 D\end{array}$ & $\begin{array}{l}\text { Single-group study. } \\
\text { Endoscopic DMR } \\
\text { procedure with } 24 \text { week } \\
\text { follow-up. }\end{array}$ & $\begin{array}{l}\text { Hydrothermal ablation } \\
\text { of the damaged mucosa } \\
\text { induces its } \\
\text { regeneration. }\end{array}$ & $\begin{array}{l}\text { Improved glycemic } \\
\text { control independent of } \\
\text { weight loss, decrease in } \\
\text { liver enzymes. }\end{array}$ & NCT02413567 \\
\hline \multirow[t]{2}{*}{$\begin{array}{l}\text { Bile acid } \\
\text { pathway }\end{array}$} & FXR agonist & $\begin{array}{l}n=931 \text { patients } \\
\text { with NASH }\end{array}$ & $\begin{array}{l}\text { Interim analysis of a } \\
\text { randomized, double- } \\
\text { blind study. OCA } \\
25 \mathrm{mg} / \mathrm{d} \text { for } 18 \text { months } \\
\text { vs. placebo. }\end{array}$ & $\begin{array}{l}\text { Restore microbiota } \\
\text { composition, barriers } \\
\text { function while reducing } \\
\text { inflammation and } \\
\text { translocation. }\end{array}$ & $\begin{array}{l}\text { Improved fibrosis and } \\
\text { components of NASH } \\
\text { disease activity. }\end{array}$ & NCT02548351 \\
\hline & FGF19 analog & $\begin{array}{l}n=43 \text { patients } \\
\text { with } \mathrm{NASH}\end{array}$ & $\begin{array}{l}\text { Open-label study. } \\
\text { NGM282 } 1 \text { mg and } \\
3 \text { mg/d for } 12 \text { weeks. }\end{array}$ & $\begin{array}{l}\text { Inhibits de novo bile } \\
\text { acid synthesis, } \\
\text { improving insulin } \\
\text { sensitivity and reducing } \\
\text { inflammation. }\end{array}$ & $\begin{array}{l}\text { Reduced NAS and } \\
\text { fibrosis scores, } \\
\text { improvements in serum } \\
\text { and imaging markers. }\end{array}$ & NCT02443116 \\
\hline
\end{tabular}

Abbreviations: BMI, body mass index; DMR, duodenal mucosal resurfacing; NAFLD, nonalcoholic fatty liver disease; NASH, nonalcoholic steatohepatitis; SCFA, short-chain fatty acid; T2D, type 2 diabetes. 
alterations of the GM or microbial metabolites should be further investigated to establish the basis for precision medicine for NAFLD.

\section{Main Concepts and Learning Points}

- A disrupted gut-liver axis contributes to NAFLD development through alteration in microbiota, changes in microbial-derived metabolites, appearance of translocation and endotoxemia due to gut barrier damage, and changes in hormones and bile acid signaling. These changes lead to immune and metabolic disturbances inducing steatosis, inflammation, and fibrosis, key events in the progression of NAFLD.

- The complex relationship between the host, the microbiota, and the external environment limits the impact of every study and must be taken into account along with other limitations in the experimental design; unified research standards are needed.

- Promising therapeutics targeting the gut-liver axis for NAFLD are underway, and they, together with noninvasive predictive biomarkers obtained by current multiomics approaches, will establish the basis of future precision medicine for NAFLD.

Funding

This project has been partially funded by the "Asociación Española para el Estudio del Hígado" (Beca de Aprendizaje de Nuevas Tecnologías) and the "Spanish Ministry of Economy, Innovation, and Competition, Instituto de Salud Carlos III" (PI19/00589). The funders have not had any role in the design, writing, or interpretation of this project.

\section{Conflict of Interest}

Dr. Rescigno reports grants from Intercept Pharmaceuticals, during the conduct of the study; grants from Gelesis, grants from Kraft-Heinz, outside the submitted work. Dr. Romero-Gómez reports grants from Intercept, grants from Gilead Sciences, personal fees from Shionogi, personal fees from Alfa Wassermann, personal fees from Prosciento, personal fees from Kaleido, personal fees from Novo Nordisk, personal fees from MSD, personal fees from BMS, personal fees from Allergan, personal fees from Boehringer-Ingelheim, personal fees from Zydus, personal fees from Intercept Pharma, personal fees from Gilead Science, outside the submitted work.

\section{References}

1 Anstee QM, Mantovani A, Tilg H, Targher G. Risk of cardiomyopathy and cardiac arrhythmias in patients with nonalcoholic fatty liver disease. Nat Rev Gastroenterol Hepatol 2018;15(07): 425-439

2 Weinstein G, Zelber-Sagi S, Preis SR, et al. Association of nonalcoholic fatty liver disease with lower brain volume in healthy middle-aged adults in the Framingham Study. JAMA Neurol 2018;75(01):97-104

3 VanWagner LB, Rinella ME. Extrahepatic manifestations of nonalcoholic fatty liver disease. Curr Hepatol Rep 2016;15(02): 75-85
4 Schuppan D, Surabattula R, Wang XY. Determinants of fibrosis progression and regression in NASH. J Hepatol 2018;68(02): 238-250

5 McPherson S, Hardy T, Henderson E, Burt AD, Day CP, Anstee QM. Evidence of NAFLD progression from steatosis to fibrosingsteatohepatitis using paired biopsies: implications for prognosis and clinical management. J Hepatol 2015;62(05):1148-1155

6 Czaja MJ. Function of autophagy in nonalcoholic fatty liver disease. Dig Dis Sci 2016;61(05):1304-1313

7 Buzzetti E, Pinzani M, Tsochatzis EA. The multiple-hit pathogenesis of non-alcoholic fatty liver disease (NAFLD). Metabolism 2016;65(08):1038-1048

8 Caussy C, Tripathi A, Humphrey G, et al. A gut microbiome signature for cirrhosis due to nonalcoholic fatty liver disease. Nat Commun 2019;10(01):1406

9 Le Roy T, Llopis M, Lepage P, et al. Intestinal microbiota determines development of non-alcoholic fatty liver disease in mice. Gut 2013;62(12):1787-1794

10 Arab JP, Karpen SJ, Dawson PA, Arrese M, Trauner M. Bile acids and nonalcoholic fatty liver disease: molecular insights and therapeutic perspectives. Hepatology 2017;65(01):350-362

11 Cho MS, Kim SY, Suk KT, Kim BY. Modulation of gut microbiome in nonalcoholic fatty liver disease: pro-, pre-, syn-, and antibiotics. J Microbiol 2018;56(12):855-867

12 Stärkel P, Schnabl B. Bidirectional communication between liver and gut during alcoholic liver disease. Semin Liver Dis 2016;36 (04):331-339

13 Milosevic I, Vujovic A, Barac A, et al. Gut-liver axis, gut microbiota, and its modulation in the management of liver diseases: a review of the literature. Int J Mol Sci 2019;20(02):E395

14 Grabherr F, Grander C, Effenberger M, Adolph TE, Tilg H. Gut dysfunction and non-alcoholic fatty liver disease. Front Endocrinol (Lausanne) 2019;10:611

15 Bäckhed F, Ding H, Wang T, et al. The gut microbiota as an environmental factor that regulates fat storage. Proc Natl Acad Sci U S A 2004;101(44):15718-15723

16 Rabot S, Membrez M, Bruneau A, et al. Germ-free C57BL/6J mice are resistant to high-fat-diet-induced insulin resistance and have altered cholesterol metabolism. FASEB J 2010;24(12):4948-4959

17 Zeng H, Liu J, Jackson MI, Zhao F-Q Yan L, Combs GF Jr. Fatty liver accompanies an increase in lactobacillus species in the hind gut of C57BL/6 mice fed a high-fat diet. J Nutr 2013;143(05): 627-631

18 Spencer MD, Hamp TJ, Reid RW, Fischer LM, Zeisel SH, Fodor AA. Association between composition of the human gastrointestinal microbiome and development of fatty liver with choline deficiency. Gastroenterology 2011;140(03):976-986

19 Loomba R, Seguritan V, Li W, et al. Gut microbiome-based metagenomic signature for non-invasive detection of advanced fibrosis in human nonalcoholic fatty liver disease. Cell Metab 2017;25(05):1054.e5-1062.e5

20 Mouries J, Brescia P, Silvestri A, et al. Microbiota-driven gut vascular barrier disruption is a prerequisite for non-alcoholic steatohepatitis development. J Hepatol 2019;71(06):1216-1228

21 Nier A, Engstler AJ, Maier IB, Bergheim I. Markers of intestinal permeability are already altered in early stages of non-alcoholic fatty liver disease: Studies in children. PLoS One 2017;12(09): e0183282

22 Kolodziejczyk AA, Zheng D, Shibolet O, Elinav E. The role of the microbiome in NAFLD and NASH. EMBO Mol Med 2019;11(02): e9302

23 Høverstad T, Midtvedt T. Short-chain fatty acids in germfree mice and rats. J Nutr 1986;116(09):1772-1776

24 Maslowski KM, Vieira AT, Ng A, et al. Regulation of inflammatory responses by gut microbiota and chemoattractant receptor GPR43. Nature 2009;461(7268):1282-1286

25 Zhou D, Fan J-G. Microbial metabolites in non-alcoholic fatty liver disease. World J Gastroenterol 2019;25(17):2019-2028 
26 Zhao L, Zhang F, Ding X, et al. Gut bacteria selectively promoted by dietary fibers alleviate type 2 diabetes. Science 2018;359 (6380):1151-1156

27 Zhou D, Chen Y-W, Zhao Z-H, et al. Sodium butyrate reduces high-fat diet-induced non-alcoholic steatohepatitis through upregulation of hepatic GLP-1R expression. Exp Mol Med 2018;50(12):1-12

28 Kimura I, Ozawa K, Inoue D, et al. The gut microbiota suppresses insulin-mediated fat accumulation via the short-chain fatty acid receptor GPR43. Nat Commun 2013;4:1829

29 Gao Z, Yin J, Zhang J, et al. Butyrate improves insulin sensitivity and increases energy expenditure in mice. Diabetes 2009;58 (07):1509-1517

30 den Besten G, van Eunen K, Groen AK, Venema K, Reijngoud D-J, Bakker BM. The role of short-chain fatty acids in the interplay between diet, gut microbiota, and host energy metabolism. J Lipid Res 2013;54(09):2325-2340

31 Qin J, Li Y, Cai Z, et al. A metagenome-wide association study of gut microbiota in type 2 diabetes. Nature 2012;490(7418):55-60

32 Cortez-Pinto H, Jesus L, Barros H, Lopes C, Moura MC, Camilo ME. How different is the dietary pattern in non-alcoholic steatohepatitis patients? Clin Nutr 2006;25(05):816-823

33 Rocha R, Cotrim HP, Siqueira AC, Floriano S. Non alcoholic fatty liver disease: treatment with soluble fibres [in Portuguese]. Arq Gastroenterol 2007;44(04):350-352

34 Lu Y, Fan C, Li P, Lu Y, Chang X, Qi K. Short chain fatty acids prevent high-fat-diet-induced obesity in mice by regulating $\mathrm{G}$ protein-coupled receptors and gut microbiota. Sci Rep 2016; 6:37589

35 Chambers ES, Viardot A, Psichas A, et al. Effects of targeted delivery of propionate to the human colon on appetite regulation, body weight maintenance and adiposity in overweight adults. Gut 2015;64(11):1744-1754

36 Schwiertz A, Taras D, Schäfer K, et al. Microbiota and SCFA in lean and overweight healthy subjects. Obesity (Silver Spring) 2010;18 (01):190-195

37 Wahlström A, Sayin SI, Marschall H-U, Bäckhed F. Intestinal crosstalk between bile acids and microbiota and its impact on host metabolism. Cell Metab 2016;24(01):41-50

38 Sayin SI, Wahlström A, Felin J, et al. Gut microbiota regulates bile acid metabolism by reducing the levels of tauro-beta-muricholic acid, a naturally occurring FXR antagonist. Cell Metab 2013;17(02):225-235

39 Kakiyama G, Pandak WM, Gillevet PM, et al. Modulation of the fecal bile acid profile by gut microbiota in cirrhosis. J Hepatol 2013;58(05):949-955

40 Ferslew BC, Xie G, Johnston CK, et al. Altered bile acid metabolome in patients with nonalcoholic steatohepatitis. Dig Dis Sci 2015;60(11):3318-3328

41 Long SL, Gahan CGM, Joyce SA. Interactions between gut bacteria and bile in health and disease. Mol Aspects Med 2017;56:54-65

42 Ticho AL, Malhotra P, Dudeja PK, Gill RK, Alrefai WA. Bile acid receptors and gastrointestinal functions. Liver Res 2019;3(01): 31-39

43 Gonzalez FJ, Jiang C, Xie C, Patterson AD. Intestinal farnesoid X receptor signaling modulates metabolic disease. Dig Dis 2017;35 (03):178-184

44 Gadaleta RM, van Erpecum KJ, Oldenburg B, et al. Farnesoid X receptor activation inhibits inflammation and preserves the intestinal barrier in inflammatory bowel disease. Gut 2011;60 (04):463-472

45 Parséus A, Sommer N, Sommer F, et al. Microbiota-induced obesity requires farnesoid X receptor. Gut 2017;66(03):429-437

46 Jiang C, Xie C, Li F, et al. Intestinal farnesoid X receptor signaling promotes nonalcoholic fatty liver disease. J Clin Invest 2015;125 (01):386-402

47 Li F, Jiang C, Krausz KW, et al. Microbiome remodelling leads to inhibition of intestinal farnesoid $\mathrm{X}$ receptor signalling and decreased obesity. Nat Commun 2013;4:2384
48 Lund ML, Sorrentino G, Egerod KL, et al. L-Cell differentiation is induced by bile acids through GPBAR1 and paracrine GLP-1 and serotonin signaling. Diabetes 2020;69(04):614-623

49 Alemi F, Poole DP, Chiu J, et al. The receptor TGR5 mediates the prokinetic actions of intestinal bile acids and is required for normal defecation in mice. Gastroenterology 2013;144(01):145-154

50 Broeders EPM, Nascimento EBM, Havekes B, et al. The bile acid chenodeoxycholic acid increases human brown adipose tissue activity. Cell Metab 2015;22(03):418-426

51 Ockenga J, Valentini L, Schuetz T, et al. Plasma bile acids are associated with energy expenditure and thyroid function in humans. J Clin Endocrinol Metab 2012;97(02):535-542

52 Volynets V, Küper MA, Strahl S, et al. Nutrition, intestinal permeability, and blood ethanol levels are altered in patients with nonalcoholic fatty liver disease (NAFLD). Dig Dis Sci 2012; 57(07):1932-1941

53 Zhu L, Baker SS, Gill C, et al. Characterization of gut microbiomes in nonalcoholic steatohepatitis (NASH) patients: a connection between endogenous alcohol and NASH. Hepatology 2013;57 (02):601-609

54 Aragonès G, Colom-Pellicer M, Aguilar C, et al. Circulating microbiota-derived metabolites: a "liquid biopsy? Int J Obes 2019

55 Cope K, Risby T, Diehl AM. Increased gastrointestinal ethanol production in obese mice: implications for fatty liver disease pathogenesis. Gastroenterology 2000;119(05):1340-1347

56 Baker SS, Baker RD, Liu W, Nowak NJ, Zhu L. Role of alcohol metabolism in non-alcoholic steatohepatitis. PLoS One 2010;5 (03):e9570

57 Zhu R, Baker SS, Moylan CA, et al. Systematic transcriptome analysis reveals elevated expression of alcohol-metabolizing genes in NAFLD livers. J Pathol 2016;238(04):531-542

58 Engstler AJ, Aumiller T, Degen C, et al. Insulin resistance alters hepatic ethanol metabolism: studies in mice and children with non-alcoholic fatty liver disease. Gut 2016;65(09):1564-1571

59 Yuan J, Chen C, Cui J, et al. Fatty liver disease caused by highalcohol-producing Klebsiella pneumoniae. Cell Metab 2019;30 (04):675.e7-688.e7

60 Chaudhry KK, Shukla PK, Mir H, et al. Glutamine supplementation attenuates ethanol-induced disruption of apical junctional complexes in colonic epithelium and ameliorates gut barrier dysfunction and fatty liver in mice. J Nutr Biochem 2016; 27:16-26

61 Rao R. Acetaldehyde-induced barrier disruption and paracellular permeability in Caco-2 cell monolayer. Methods Mol Biol 2008; 447:171-183

62 Yan AWE, Fouts DE, Brandl J, et al. Enteric dysbiosis associated with a mouse model of alcoholic liver disease. Hepatology 2011; 53(01):96-105

63 McVicker BL, Rasineni K, Tuma DJ, McNiven MA, Casey CA. Lipid droplet accumulation and impaired fat efflux in polarized hepatic cells: consequences of ethanol metabolism. Int J Hepatol 2012;2012:978136

64 Lieber CS. Hepatic, metabolic and toxic effects of ethanol: 1991 update. Alcohol Clin Exp Res 1991;15(04):573-592

65 Hoang-Yen Tran D, Hoang-Ngoc Tran D, Mattai SA, et al. Cathelicidin suppresses lipid accumulation and hepatic steatosis by inhibition of the CD36 receptor. Int J Obes 2016;40(09):1424-1434

66 Su D, Nie Y, Zhu A, et al. Vitamin D signaling through induction of paneth cell defensins maintains gut microbiota and improves metabolic disorders and hepatic steatosis in animal models. Front Physiol 2016;7:498

67 Corbin KD, Zeisel SH. Choline metabolism provides novel insights into nonalcoholic fatty liver disease and its progression. Curr Opin Gastroenterol 2012;28(02):159-165

68 Sherriff JL, O'Sullivan TA, Properzi C, Oddo J-L, Adams LA. Choline, its potential role in nonalcoholic fatty liver disease, and the case for human and bacterial genes. Adv Nutr 2016;7 (01):5-13 
69 Shih DM, Wang Z, Lee R, et al. Flavin containing monooxygenase 3 exerts broad effects on glucose and lipid metabolism and atherosclerosis. J Lipid Res 2015;56(01):22-37

70 Tang WH, Hazen SL. Microbiome, trimethylamine N-oxide, and cardiometabolic disease. Transl Res 2017;179:108-115

71 Koeth RA, Wang Z, Levison BS, et al. Intestinal microbiota metabolism of L-carnitine, a nutrient in red meat, promotes atherosclerosis. Nat Med 2013;19(05):576-585

72 Chen YM, Liu Y, Zhou RF, et al. Associations of gut-flora-dependent metabolite trimethylamine-N-oxide, betaine and choline with non-alcoholic fatty liver disease in adults. Sci Rep 2016;6:19076

73 Barrea L, Annunziata G, Muscogiuri G, et al. Trimethylamine-Noxide (TMAO) as novel potential biomarker of early predictors of metabolic syndrome. Nutrients 2018;10(12):E1971

74 Wang Z, Roberts AB, Buffa JA, et al. Non-lethal inhibition of gut microbial trimethylamine production for the treatment of atherosclerosis. Cell 2015;163(07):1585-1595

75 Zimmermann E, Anty R, Tordjman J, et al. C-reactive protein levels in relation to various features of non-alcoholic fatty liver disease among obese patients. J Hepatol 2011;55(03):660-665

76 Pihlajamäki J, Kuulasmaa T, Kaminska D, et al. Serum interleukin 1 receptor antagonist as an independent marker of non-alcoholic steatohepatitis in humans. J Hepatol 2012;56(03):663-670

77 Lefere S, Van de Velde F, Devisscher L, et al. Serum vascular cell adhesion molecule- 1 predicts significant liver fibrosis in nonalcoholic fatty liver disease. Int J Obes 2017;41(08):1207-1213

78 Liang H, Lum H, Alvarez A, Garduno-Garcia JJ, Daniel BJ, Musi N. A low dose lipid infusion is sufficient to induce insulin resistance and a pro-inflammatory response in human subjects. PLoS One 2018;13(04):e0195810

79 Kubes P, Mehal WZ. Sterile inflammation in the liver. Gastroenterology 2012;143(05):1158-1172

80 Ertunc ME, Hotamisligil GS. Lipid signaling and lipotoxicity in metaflammation: indications for metabolic disease pathogenesis and treatment. J Lipid Res 2016;57(12):2099-2114

81 Hosogai N, Fukuhara A, Oshima K, et al. Adipose tissue hypoxia in obesity and its impact on adipocytokine dysregulation. Diabetes 2007;56(04):901-911

82 Rathinam VAK, Zhao Y, Shao F. Innate immunity to intracellular LPS. Nat Immunol 2019;20(05):527-533

83 Vijayan A, Rumbo M, Carnoy C, Sirard JC. Compartmentalized antimicrobial defenses in response to flagellin. Trends Microbiol 2018;26(05):423-435

84 Wolf AJ, Underhill DM. Peptidoglycan recognition by the innate immune system. Nat Rev Immunol 2018;18(04):243-254

85 Yiu JH, Dorweiler B, Woo CW. Interaction between gut microbiota and toll-like receptor: from immunity to metabolism. J Mol Med (Berl) 2017;95(01):13-20

86 Kazankov K, Jørgensen SMD, Thomsen KL, et al. The role of macrophages in nonalcoholic fatty liver disease and nonalcoholic steatohepatitis. Nat Rev Gastroenterol Hepatol 2019;16(03): 145-159

87 Reilly SM, Saltiel AR. Adapting to obesity with adipose tissue inflammation. Nat Rev Endocrinol 2017;13(11):633-643

88 Camargo A, Jimenez-Lucena R, Alcala-Diaz JF, et al. Postprandial endotoxemia may influence the development of type 2 diabetes mellitus: from the CORDIOPREV study. Clin Nutr 2019;38(02): 529-538

89 Pussinen PJ, Havulinna AS, Lehto M, Sundvall J, Salomaa V. Endotoxemia is associated with an increased risk of incident diabetes. Diabetes Care 2011;34(02):392-397

90 Mehta NN, McGillicuddy FC, Anderson PD, et al. Experimental endotoxemia induces adipose inflammation and insulin resistance in humans. Diabetes 2010;59(01):172-181

91 Cani PD, Bibiloni R, Knauf C, et al. Changes in gut microbiota control metabolic endotoxemia-induced inflammation in highfat diet-induced obesity and diabetes in mice. Diabetes 2008;57 (06):1470-1481
92 Amar J, Burcelin R, Ruidavets JB, et al. Energy intake is associated with endotoxemia in apparently healthy men. Am J Clin Nutr 2008;87(05):1219-1223

93 Pang J, Xu W, Zhang X, et al. Significant positive association of endotoxemia with histological severity in 237 patients with nonalcoholic fatty liver disease. Aliment Pharmacol Ther 2017;46 (02):175-182

94 Pendyala S, Walker JM, Holt PR. A high-fat diet is associated with endotoxemia that originates from the gut. Gastroenterology 2012;142(05):1100-1101.e2

95 Cani PD, Neyrinck AM, Fava F, et al. Selective increases of bifidobacteria in gut microflora improve high-fat-diet-induced diabetes in mice through a mechanism associated with endotoxaemia. Diabetologia 2007;50(11):2374-2383

96 Fabbiano S, Suárez-Zamorano N, Chevalier C, et al. Functional gut microbiota remodeling contributes to the caloric restrictioninduced metabolic improvements. Cell Metab 2018;28(06):907. e7-921.e7

97 Vatanen T, Kostic AD, d'Hennezel E, et al;DIABIMMUNE Study Group. Variation in microbiome LPS immunogenicity contributes to autoimmunity in humans. Cell 2016;165(04):842-853

98 Fei N, Zhao L. An opportunistic pathogen isolated from the gut of an obese human causes obesity in germfree mice. ISME J 2013;7 (04):880-884

99 Clarke TB, Davis KM, Lysenko ES, Zhou AY, Yu Y, Weiser JN. Recognition of peptidoglycan from the microbiota by Nod1 enhances systemic innate immunity. Nat Med 2010;16(02): 228-231

100 Chan KL, Tam TH, Boroumand P, et al. Circulating NOD1 activators and hematopoietic NOD1 contribute to metabolic inflammation and insulin resistance. Cell Rep 2017;18(10):2415-2426

101 Zhu W, Gregory JC, Org E, et al. Gut microbial metabolite TMAO enhances platelet hyperreactivity and thrombosis risk. Cell 2016;165(01):111-124

102 Brown JM, Hazen SL. Microbial modulation of cardiovascular disease. Nat Rev Microbiol 2018;16(03):171-181

103 Roager HM, Vogt JK, Kristensen M, et al. Whole grain-rich diet reduces body weight and systemic low-grade inflammation without inducing major changes of the gut microbiome: a randomised cross-over trial. Gut 2019;68(01):83-93

104 Furusawa Y, Obata Y, Fukuda S, et al. Commensal microbederived butyrate induces the differentiation of colonic regulatory T cells. Nature 2013;504(7480):446-450

105 Rescigno M. The microbiota revolution: excitement and caution. Eur J Immunol 2017;47(09):1406-1413

106 Bergström JH, Birchenough GM, Katona G, et al. Gram-positive bacteria are held at a distance in the colon mucus by the lectinlike protein ZG16. Proc Natl Acad Sci U S A 2016;113(48): 13833-13838

107 Okumura R, Kurakawa T, Nakano T, et al. Lypd8 promotes the segregation of flagellated microbiota and colonic epithelia. Nature 2016;532(7597):117-121

108 Jakobsson HE, Rodríguez-Piñeiro AM, Schütte A, et al. The composition of the gut microbiota shapes the colon mucus barrier. EMBO Rep 2015;16(02):164-177

109 Groschwitz KR, Hogan SP. Intestinal barrier function: molecular regulation and disease pathogenesis. J Allergy Clin Immunol 2009;124(01):3-20, quiz 21-22

110 Schroeder BO, Birchenough GMH, Ståhlman M, et al. Bifidobacteria or fiber protects against diet-induced microbiota-mediated colonic mucus deterioration. Cell Host Microbe 2018;23(01):27. e7-40.e7

111 Desai MS, Seekatz AM, Koropatkin NM, et al. A dietary fiberdeprived gut microbiota degrades the colonic mucus barrier and enhances pathogen susceptibility. Cell 2016;167(05):1339.e21$-1353 . \mathrm{e} 21$

112 Wrzosek L, Miquel S, Noordine ML, et al. Bacteroides thetaiotaomicron and Faecalibacterium prausnitzii influence the 
production of mucus glycans and the development of goblet cells in the colonic epithelium of a gnotobiotic model rodent. BMC Biol 2013;11:61

113 Martínez-López M, Iborra S, Conde-Garrosa R, et al. Microbiota sensing by Mincle-Syk axis in dendritic cells regulates interleukin-17 and -22 production and promotes intestinal barrier integrity. Immunity 2019;50(02):446.e9-461.e9

114 Sonnenberg GF, Monticelli LA, Alenghat T, et al. Innate lymphoid cells promote anatomical containment of lymphoid-resident commensal bacteria. Science 2012;336(6086):1321-1325

115 Stockinger B, Omenetti S. The dichotomous nature of T helper 17 cells. Nat Rev Immunol 2017;17(09):535-544

116 Hartmann P, Seebauer CT, Mazagova M, et al. Deficiency of intestinal mucin-2 protects mice from diet-induced fatty liver disease and obesity. Am J Physiol Gastrointest Liver Physiol 2016;310(05):G310-G322

117 Kurashima Y, Kiyono H. Mucosal ecological network of epithelium and immune cells for gut homeostasis and tissue healing. Annu Rev Immunol 2017;35:119-147

118 Brown EM, Sadarangani M, Finlay BB. The role of the immune system in governing host-microbe interactions in the intestine. Nat Immunol 2013;14(07):660-667

119 Tilg H, Zmora N, Adolph TE, Elinav E. The intestinal microbiota fuelling metabolic inflammation. Nat Rev Immunol 2020;20 (01):40-54

120 Giorgio V, Miele L, Principessa L, et al. Intestinal permeability is increased in children with non-alcoholic fatty liver disease, and correlates with liver disease severity. Dig Liver Dis 2014;46(06): 556-560

121 Miele L, Valenza V, La Torre G, et al. Increased intestinal permeability and tight junction alterations in nonalcoholic fatty liver disease. Hepatology 2009;49(06):1877-1887

122 Thaiss CA, Levy M, Grosheva I, et al. Hyperglycemia drives intestinal barrier dysfunction and risk for enteric infection. Science 2018;359(6382):1376-1383

123 Johnson AM, Costanzo A, Gareau MG, et al. High fat diet causes depletion of intestinal eosinophils associated with intestinal permeability. PLoS One 2015;10(04):e0122195

124 Genser L, Aguanno D, Soula HA, et al. Increased jejunal permeability in human obesity is revealed by a lipid challenge and is linked to inflammation and type 2 diabetes. J Pathol 2018;246 (02):217-230

125 Monteiro-Sepulveda M, Touch S, Mendes-Sá C, et al. Jejunal T cell inflammation in human obesity correlates with decreased enterocyte insulin signaling. Cell Metab 2015;22(01):113-124

126 Garidou L, Pomié C, Klopp P, et al. The gut microbiota regulates intestinal CD4 T cells expressing RORyt and controls metabolic disease. Cell Metab 2015;22(01):100-112

127 Ghoshal S, Witta J, Zhong J, de Villiers W, Eckhardt E. Chylomicrons promote intestinal absorption of lipopolysaccharides. J Lipid Res 2009;50(01):90-97

128 Laugerette F, Vors C, Géloën A, et al. Emulsified lipids increase endotoxemia: possible role in early postprandial low-grade inflammation. J Nutr Biochem 2011;22(01):53-59

129 Guo S, Al-Sadi R, Said HM, Ma TY. Lipopolysaccharide causes an increase in intestinal tight junction permeability in vitro and in vivo by inducing enterocyte membrane expression and localization of TLR-4 and CD14. Am J Pathol 2013;182(02):375-387

130 Rahman K, Desai C, lyer SS, et al. Loss of junctional adhesion molecule a promotes severe steatohepatitis in mice on a diet high in saturated fat, fructose, and cholesterol. Gastroenterology 2016;151(04):733.e12-746.e12

131 Zhao Z-H, Xin F-Z, Xue Y, et al. Indole-3-propionic acid inhibits gut dysbiosis and endotoxin leakage to attenuate steatohepatitis in rats. Exp Mol Med 2019;51(09):1-14

132 Spadoni I, Zagato E, Bertocchi A, et al. A gut-vascular barrier controls the systemic dissemination of bacteria. Science 2015; 350(6262):830-834
133 Spadoni I, Pietrelli A, Pesole G, Rescigno M. Gene expression profile of endothelial cells during perturbation of the gut vascular barrier. Gut Microbes 2016;7(06):540-548

134 Spadoni I, Fornasa G, Rescigno M. Organ-specific protection mediated by cooperation between vascular and epithelial barriers. Nat Rev Immunol 2017;17(12):761-773

135 Cheng C, Tan J, Qian W, Zhang L, Hou X. Gut inflammation exacerbates hepatic injury in the high-fat diet induced NAFLD mouse: attention to the gut-vascular barrier dysfunction. Life Sci 2018;209:157-166

136 Sorribas M, Jakob MO, Yilmaz B, et al. FXR modulates the gutvascular barrier by regulating the entry sites for bacterial translocation in experimental cirrhosis. J Hepatol 2019;71(06): $1126-1140$

137 Angulo P, Kleiner DE, Dam-Larsen S, et al. Liver fibrosis, but no other histologic features, is associated with long-term outcomes of patients with nonalcoholic fatty liver disease. Gastroenterology 2015;149(02):389.e10-397.e10

138 Gangarapu V, Ince AT, Baysal B, et al. Efficacy of rifaximin on circulating endotoxins and cytokines in patients with nonalcoholic fatty liver disease. Eur J Gastroenterol Hepatol 2015;27 (07):840-845

139 Boursier J, Mueller O, Barret M, et al. The severity of nonalcoholic fatty liver disease is associated with gut dysbiosis and shift in the metabolic function of the gut microbiota. Hepatology 2016;63 (03):764-775

140 Tripathi A, Debelius J, Brenner DA, et al. The gut-liver axis and the intersection with the microbiome. Nat Rev Gastroenterol Hepatol 2018;15(07):397-411

141 Douhara A, Moriya K, Yoshiji H, et al. Reduction of endotoxin attenuates liver fibrosis through suppression of hepatic stellate cell activation and remission of intestinal permeability in a rat non-alcoholic steatohepatitis model. Mol Med Rep 2015;11(03): 1693-1700

142 Abdelmalek MF, Suzuki A, Guy C, et al;Nonalcoholic Steatohepatitis Clinical Research Network. Increased fructose consumption is associated with fibrosis severity in patients with nonalcoholic fatty liver disease. Hepatology 2010;51(06): 1961-1971

143 Jang C, Hui S, Lu W, et al. The small intestine converts dietary fructose into glucose and organic acids. Cell Metab 2018;27(02): 351.e3-361.e3

144 Csak T, Ganz M, Pespisa J, Kodys K, Dolganiuc A, Szabo G. Fatty acid and endotoxin activate inflammasomes in mouse hepatocytes that release danger signals to stimulate immune cells. Hepatology 2011;54(01):133-144

145 Seki E, Schnabl B. Role of innate immunity and the microbiota in liver fibrosis: crosstalk between the liver and gut. J Physiol 2012; 590(03):447-458

146 Wree A, McGeough MD, Peña CA, et al. NLRP3 inflammasome activation is required for fibrosis development in NAFLD. J Mol Med (Berl) 2014;92(10):1069-1082

147 Fouts DE, Torralba M, Nelson KE, Brenner DA, Schnabl B. Bacterial translocation and changes in the intestinal microbiome in mouse models of liver disease. J Hepatol 2012;56(06):1283-1292

148 Seki E, De Minicis S, Osterreicher CH, et al. TLR4 enhances TGFbeta signaling and hepatic fibrosis. Nat Med 2007;13(11): 1324-1332

149 Seki E, De Minicis S, Gwak GY, et al. CCR1 and CCR5 promote hepatic fibrosis in mice. J Clin Invest 2009;119(07): $1858-1870$

150 Luo X, Li H, Ma L, et al. Expression of STING is increased in liver tissues from patients with NAFLD and promotes macrophagemediated hepatic inflammation and fibrosis in mice. Gastroenterology 2018;155(06):1971.e4-1984.e4

151 Seki E, Schwabe RF. Hepatic inflammation and fibrosis: functional links and key pathways. Hepatology 2015;61(03): 1066-1079 
152 Zong H, Armoni M, Harel C, Karnieli E, Pessin JE. Cytochrome P450 CYP2E1 knockout mice are protected against high-fat dietinduced obesity and insulin resistance. Am J Physiol Endocrinol Metab 2012;302(05):E532-E539

153 Sinha R, Abnet CC, White O, Knight R, Huttenhower C. The microbiome quality control project: baseline study design and future directions. Genome Biol 2015;16:276

154 Cui J, Chen C-H, Lo M-T, et al;For The Genetics Of Nafld In Twins Consortium. Shared genetic effects between hepatic steatosis and fibrosis: a prospective twin study. Hepatology 2016;64(05): 1547-1558

155 Goodrich JK, Davenport ER, Beaumont M, et al. Genetic determinants of the gut microbiome in UK twins. Cell Host Microbe 2016;19(05):731-743

156 Hartmann P, Chu H, Duan Y, Schnabl B. Gut microbiota in liver disease: too much is harmful, nothing at all is not helpful either. Am J Physiol Gastrointest Liver Physiol 2019;316(05): G563-G573

$157 \mathrm{Oh} \mathrm{J-H,} \mathrm{Schueler} \mathrm{KL,} \mathrm{Stapleton} \mathrm{DS,} \mathrm{et} \mathrm{al.} \mathrm{Secretion} \mathrm{of} \mathrm{recombinant}$ interleukin-22 by engineered Lactobacillus reuteri reduces fatty liver disease in a mouse model of diet-induced obesity. MSphere 2020;5(03):e00183-e20

158 Duan Y, Llorente C, Lang S, et al. Bacteriophage targeting of gut bacterium attenuates alcoholic liver disease. Nature 2019;575 (7783):505-511

159 Honda T, Ishigami M, Luo F, et al. Branched-chain amino acids alleviate hepatic steatosis and liver injury in choline-deficient high-fat diet induced NASH mice. Metabolism 2017;69:177-187

160 Kaikkonen JE, Würtz P, Suomela E, et al. Metabolic profiling of fatty liver in young and middle-aged adults: cross-sectional and prospective analyses of the Young Finns Study. Hepatology 2017; 65(02):491-500

161 Krishnan S, Ding Y, Saedi N, et al. Gut microbiota-derived tryptophan metabolites modulate inflammatory response in hepatocytes and macrophages. Cell Rep 2018;23(04):1099-1111

162 Natividad JM, Agus A, Planchais J, et al. Impaired aryl hydrocarbon receptor ligand production by the gut microbiota is a key factor in metabolic syndrome. Cell Metab 2018;28(05):737. e4-749.e4

163 El Hadi H, Vettor R, Rossato M. Vitamin E as a treatment for nonalcoholic fatty liver disease: reality or myth? Antioxidants 2018;7(01):12

164 Christensen K, Lawler T, Mares J. Dietary carotenoids and nonalcoholic fatty liver disease among US adults, NHANES 2003-2014. Nutrients 2019;11(05):1101

165 Anhê FF, Nachbar RT, Varin TV, et al. A polyphenol-rich cranberry extract reverses insulin resistance and hepatic steatosis independently of body weight loss. Mol Metab 2017;6(12):1563-1573
166 Kalantar-Zadeh K, Berean KJ, Burgell RE, Muir JG, Gibson PR. Intestinal gases: influence on gut disorders and the role of dietary manipulations. Nat Rev Gastroenterol Hepatol 2019;16 (12):733-747

167 Strandwitz P. Neurotransmitter modulation by the gut microbiota. Brain Res 2018;1693(Pt B):128-133

168 Michail S, Lin M, Frey MR, et al. Altered gut microbial energy and metabolism in children with non-alcoholic fatty liver disease. FEMS Microbiol Ecol 2015;91(02):1-9

169 Raman M, Ahmed I, Gillevet PM, et al. Fecal microbiome and volatile organic compound metabolome in obese humans with nonalcoholic fatty liver disease. Clin Gastroenterol Hepatol 2013;11(07):868-75.e1, 3

170 Wong VW-S, Tse C-H, Lam TT-Y, et al. Molecular characterization of the fecal microbiota in patients with nonalcoholic steatohepatitis-a longitudinal study. PLoS One 2013;8(04):e62885

171 Hoyles L, Fernández-Real JM, Federici M, et al. Molecular phenomics and metagenomics of hepatic steatosis in non-diabetic obese women. Nat Med 2018;24(07):1070-1080

172 Shen F, Zheng R-D, Sun X-Q, Ding W-J, Wang X-Y, Fan J-G. Gut microbiota dysbiosis in patients with non-alcoholic fatty liver disease. Hepatobiliary Pancreat Dis Int 2017;16(04):375-381

173 Del Chierico F, Nobili V, Vernocchi P, et al. Gut microbiota profiling of pediatric nonalcoholic fatty liver disease and obese patients unveiled by an integrated meta-omics-based approach. Hepatology 2017;65(02):451-464

174 Mouzaki M, Comelli EM, Arendt BM, et al. Intestinal microbiota in patients with nonalcoholic fatty liver disease. Hepatology 2013;58(01):120-127

175 Bajaj JS, Heuman DM, Hylemon PB, et al. Altered profile of human gut microbiome is associated with cirrhosis and its complications. J Hepatol 2014;60(05):940-947

176 Wang B, Jiang X, Cao M, et al. Altered fecal microbiota correlates with liver biochemistry in nonobese patients with non-alcoholic fatty liver disease. Sci Rep 2016;6(01):32002

177 Li F, Sun G, Wang Z, et al. Characteristics of fecal microbiota in non-alcoholic fatty liver disease patients. Sci China Life Sci 2018; 61(07):770-778

178 Jiang W, Wu N, Wang X, et al. Dysbiosis gut microbiota associated with inflammation and impaired mucosal immune function in intestine of humans with non-alcoholic fatty liver disease. Sci Rep 2015;5:8096

179 Da Silva HE, Teterina A, Comelli EM, et al. Nonalcoholic fatty liver disease is associated with dysbiosis independent of body mass index and insulin resistance. Sci Rep 2018;8(01):1466

180 Demir M, Lang S, Martin A, et al. Phenotyping non-alcoholic fatty liver disease by the gut microbiota: ready for prime time? J Gastroenterol Hepatol 2020 